e-Jurnal Ilmiah BIOSAINTROPIS (BIOSCIENCE-TROPIC)

Volume 6/ No.: 2 / Halaman 1 - 10 / Januari Tahun 2021

ISSN : 2460-9455 (e) - 2338-2805(p)

\title{
Daya Dukung Fisik Kegiatan Ekowisata Pantai Kondang Merak, Kabupaten Malang - Jawa Timur
}

\author{
Physical Carrying Capacity of Ecotourism Activity in Kondang Merak \\ Beach, Malang - East Java \\ Silfi Anggraeni ${ }^{1 *}$, Luchman Hakim $^{2 * *}$ ) \\ 1,2 Jurusan Biologi Fakultas Matematika dan Ilmu Pengetahuan Alam Universitas Brawijaya, Indonesia
}

\begin{abstract}
ABSTRAK
Pantai Kondang Merak merupakan salah satu pantai yang memiliki potensi ekowisata bahari yang memiliki berbagai macam kegiatan wisata dengan jumlah pengunjung yang terus mengalami peningkatan. Oleh sebab itu perlu dilakukan analisis daya dukung fisiknya sehingga kelestarian sumber daya alam di Kondang Merak dapat mendukung aktivitas ekowisata secara berkelanjutan. Penelitian ini bertujuan untuk menganalisis daya dukung fisik ekosistem akuatik dan terestrial di Pantai Kondang Merak. Penelitian menggunakan metode observasi dengan teknik wawancara semi terstruktur. Analisis data daya dukung fisik ditampilkan secara deskriptif dalam bentuk tabel. Hasil penelitian menunjukkan bahwa kegiatan wisata dengan memanfaatkan ekosistem akuatik terdiri dari kegiatan selam dan snorkeling. Nilai daya dukung fisik kegiatan selam yaitu 3 orang/hari dan daya dukung fisik untuk kegiatan snorkeling yaitu sebanyak 40 orang/hari. Selain itu wisata terrestrial memiliki nilai daya dukung fisik sebanyak 1000 orang/hari. Namun, jumlah pengunjung dapat melebihi kapasitas daya dukung fisik sehingga diperlukan pembatasan jumlah pengunjung agar kelestarian ekosistem didalamnya dapat terjaga.
\end{abstract}

Kata kunci: daya dukung fisik, ekowisata, kondang merak

\begin{abstract}
Kondang Merak Beach is one of the beaches that has the potential for marine ecotourism which has various kinds of tourist activities with an increasing number of visitors. Therefore it is necessary to analyze its physical carrying capacity so that the preservation of natural resources in Kondang Merak can support ecotourism activities in a sustainable. This study aims to analyze the physical carrying capacity of the aquatic and terrestrial ecosystems at Kondang Merak Beach. This study used the observation method with semi-structured interview techniques. Physical carrying capacity data analysis is shown descriptively in tabular form. The results showed that tourism activities utilizing the aquatic ecosystem consisted of diving and snorkeling activities. The value of the physical carrying capacity of the diving activity is 3 people / day and the physical carrying capacity for snorkeling is 40 people / day. In addition, terrestrial tourism has a physical carrying capacity of 1000 people / day. However, the number of visitors can exceed the physical carrying capacity so that it is necessary to limit the number of visitors so that the sustainability of the ecosystem in it can be maintained.
\end{abstract}

Keywords: ecotourism, kondang merak, physical carrying capasity

*) Silfi Anggraeni, Jurusan Biologi, FMIPA UB, Jl. Veteran , Malang 65145, +6285715704157 and email:silfi.anggra@student.ub.ac.id

${ }^{* *)}$ Prof. Luchman Hakim, S.Si. M,Agr., Ph.D., Jurusan Biologi, FMIPA UB, Jl. Veteran, Malang 65145, +6281249787187 and luchman@ub.ac.id

Diterima Tanggal 3 Juni 2020 - Dipublikasikan Tanggal 25 Januari 2021 
e-Jurnal Ilmiah BIOSAINTROPIS (BIOSCIENCE-TROPIC)

Volume 6/ No.: 2 / Halaman 1 - 10 / Januari Tahun 2021

ISSN : 2460-9455 (e) - 2338-2805(p)

\section{Pendahuluan}

Indonesia merupakan negara kepulauan dengan panjang garis pantai mencapai $544.716 \mathrm{~km}$ yang membuat pengembangan wisata pantai menjadi sumber daya yang sangat besar [1]. Salah satu upaya pemanfaatan sumber daya tersebut adalah dengan mengembangkan pariwisata dengan konsep ekowisata. Ekowisata merupakan kegiatan antara perjalanan wisata alam yang memiliki visi dan misi konservasi dan kecintaan lingkungan. Selain untuk menikmati keindahan alam juga melibatkan unsur pendidikan dan dukungan terhadap usaha konservasi. Kegiatan ekowisata diharapkan berdampak positif terhadap kelestarian lingkungan dan meningkatkan perekonomian masyarakat local [2]. Salah satu jenis kegiatan ekowisata yaitu ekowisata bahari. Ekowisata bahari merupakan jenis wisata yang berkaitan dengan aktivitas kelautan, baik yang dilakukan di bawah laut maupun di atas permukaan laut. Kegiatan ekowisata bahari yang dapat dilakukan antara lain berperahu, berenang, snorkeling, menyelam, memancing, kegiatan olahraga pantai dan piknik menikmati atmosfer laut [3].

Aktivitas ekowisata bahari saat ini tengah menjadi tren yang dilakukan oleh para wisatawan khususnya wisatawan yang ingin menikmati habitat-habitat alamiah dan keanekaragaman hayati di dalamnya. Aktivitas wisata bahari dapat berkontribusi dalam pertumbuhan ekonomi, namun dampak negatif yang ditimbulkan yaitu dapat mengakibatkan kerusakan lingkungan seperti degradasi sumber daya pantai. Selain itu kerusakan lingkungan juga dapat disebabkan oleh lemahnya manajeman dan peran pemerintah dalam mendorong upaya konservasi [4]. Sehingga diperlukan pengaturan jumlah pengunjung di area ekowisata bahari, untuk dapat menunjang daya dukung lingkungannya agar kelestarian lingkungan tetap terjaga. Daya dukung lingkungan mengacu pada kemampuan suatu ekosistem alamiah untuk menampung jumlah wisatawan. Daya dukung lingkungan menjadi tolak ukur dalam pengelolaan wisata bahari. Meningkatnya jumlah wisatawan merupakan permasalahan utama dalam kegiatan ekowisata, sehingga pembatasan terhadap jumlah wisatawan harus didasarkan pada jumlah yang dapat ditoleransi oleh suatu kawasan [5]

Salah satu pantai yang memiliki potensi sebagai tempat ekowisata bahari yaitu pantai Kondang Merak yang terletak di bagian selatan Kabupaten Malang Jawa Timur dan berbatasan langsung dengan Samudera Hindia. Jarak tempuh kurang lebih 2 jam dan kurang lebih berjarak $63.5 \mathrm{~km}$ dari Kota Malang. Pantai Kondang Merak memiliki berbagai jenis ekosistem seperti mangrove, dan terumbu karang juga memiliki potensi flora dan fauna yang sangat besar, baik yang berada di darat maupun di laut. Pemandangan bawah air menjadi salah satu daya tarik di Kondang Merak [6]. Pemerintah Kabupaten Malang menjelaskan bahwa kawasan wisata Pantai Kondang Merak memiliki pengunjung sekitar 8.500 orang pengunjung setiap tahun, namun selama ini hanya memaksimalkan kawasan wisata Kondang Merak melalui sektor keindahan pantai serta sektor perikanan yang dihasilkan oleh para nelayan setempat [7].

Banyaknya jumlah pengunjung yang datang ke Kondang Merak untuk melakukan kegiatan diving dan snorkeling yang berpotensi mempengaruhi kelestarian sumber daya alam di area tersebut. Penelitian ini bertujuan untuk mengetahui daya dukung fisik kawasan akuatik dan terestrial dalam menunjang kegiatan wisata alam di Pantai Kondang Merak, sehingga kelestarian sumber daya alam di Kondang Merak dapat mendukung aktivitas ekowisata secara berkelanjutan.

\section{Material dan Metode}

Penelitian ini dilaksanakan pada bulan September 2019 hingga April 2020. Penelitian ini dilaksanakan di Pantai Kondang Merak, Desa Sumberbening, Kecamatan Bantur, Kabupaten Malang. Pantai Kondang Merak merupakan salah satu pantai yang terletak di sebelah selatan Kabupaten Malang pada posisi $8^{\circ} 23^{\prime}$ 50,56' LS dan $112^{\circ} 31^{\prime}$ 06,89” BT (Gambar 1) serta memiliki panjang garis pantai $500 \mathrm{~m}$ dan berbatasan langsung dengan Samudera Hindia [8]. 


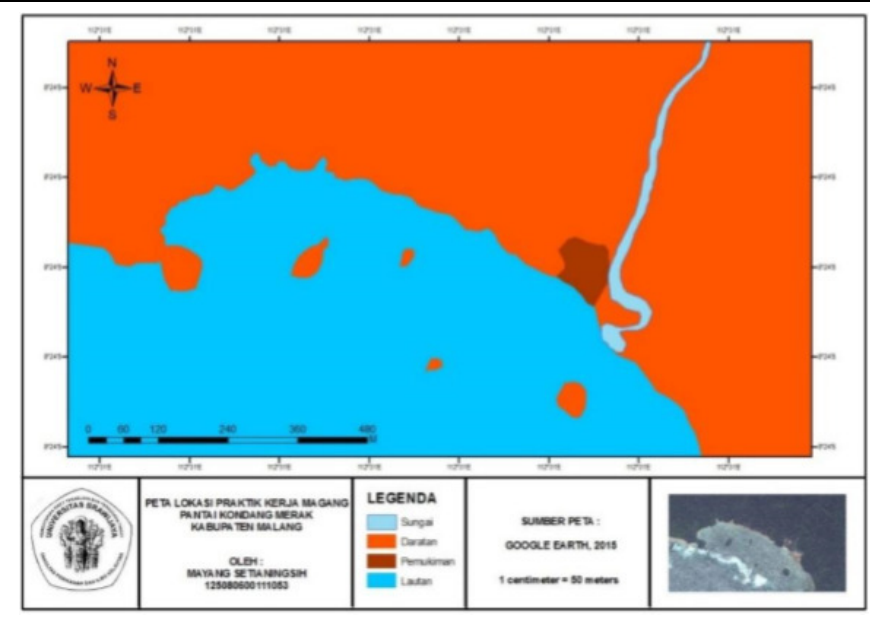

Gambar 1. Peta Pantai Kondang Merak [8]

\section{Metode}

Studi Pendahuluan: Sebelum melakukan penelitian, terlebih dahulu dilakukan perizinan kepada aparatur Desa Sumberbening serta LMDH (Lembaga Masyarakat Desa Hutan) yang terkait dengan kawasan Pantai Kondang Merak. Dilakukan koordinasi penelitian dengan Lembaga Konservasi dan Pemberdayaan Masyarakat Sahabat Alam (SALAM). Kemudian dilakukan studi pendahuluan dengan wawancara semi terstruktur kepada informan kunci untuk memperoleh informasi dan gambaran umum mengenai lokasi penelitian. Kegiatan studi pendahuluan dilakukan untuk menentukan luas area yang digunakan pada kegiatan diving dan snorkeling serta luas area yang digunakan untuk kegiatan wisata di pantai. Kegiatan ini dilakukan untuk menentukan batas-batas area kegiatan wisata alam di Kondang Merak.

Observasi: Observasi dilakukan di kawasan pantai Kondang Merak dan sekitarnya yang telah ditetapkan pada saat studi pendahuluan. Observasi yang dilakukan meliputi kegiatan wisatawan di Kondang Merak serta sarana dan prasarana yang disediakan oleh pengelola. Data yang telah dikumpulkan dianalisis dan diinterpretasikan menggunakan pendekatan kualitatif.

Wawancara: Metode wawancara digunkan untuk mengetahui mengetahui rata-rata durasi kunjungan ke lokasi tersebut serta sarana dan prasarana yang disediakan di Pantai Kondang Merak. Teknik wawancara yang digunakan yaitu wawancara semi terstruktur yang merupakan teknik wawancara dengan pedoman wawancara yang sebelumnya telah ditentukan peneliti dan akan berkembang sesuai dengan jawaban atau informasi dari narasumber.

Responden berasal dari anggota LMDH (Lembaga Masyarakat Daerah Hutan), masyarakat sekitar kawasan dan wisatawan. Jumlah responden dihitung menggunakan rumus 1 [9]:

$$
n=\frac{\mathrm{N} Z^{2} \times 0.25}{d^{2} \times(\mathrm{N}-1)+\left(Z^{2}\right) \times 0,25}
$$

Keterangan:

$\mathrm{n}$ : jumlah sampel yang diambil

$\mathrm{N}$ : jumlah populasi (yang diketahui dan diperkiran)

$\mathrm{Z}$ : Standar deviasi yang berhubungan dengan tingkat kepercayaan $(\mathrm{Z}=1.96)$

$\mathrm{d}$ : tingkat akurasi/ presisi $(10-15 \%)$

Jumlah responden dari anggota $\mathrm{LMDH}$, masyarakat sekitar kawasan dan wisatawan menggunakan tingkat akurat atau presisi sebesar 15\%. Berdasarkan persamaan 3.1 diperoleh nilai $\mathrm{n}=$ 
e-Jurnal Ilmiah BIOSAINTROPIS (BIOSCIENCE-TROPIC)

Volume 6/ No.: 2 / Halaman 1 - 10 / Januari Tahun 2021

ISSN : 2460-9455 (e) - 2338-2805(p)

42.45 dibulatkan menjadi 42 orang untuk responden wisatawan. Sedangkan responden dari anggota LMDH dan masyarakat sekitar kawasan memiliki nilai $\mathrm{n}=20.06$ dibulatkan menjadi 20 orang. Sehingga total responden dalam penelitian ini adalah 62 orang.

\section{Analisis Daya Dukung}

Analisis daya dukung yang digunakan dalam penelitian ini yaitu analisis daya dukung fisik (PCC). Perhitungan daya dukung fisik Pantai Kondang Merak dilakukan dengan menggunakan rumus $2[10][11]:$

Keterangan:

$$
\mathrm{PCC}=\mathrm{A} \times \mathrm{V} / \mathrm{a} \times \mathrm{Rf}
$$

PCC : Physical Carrying Capacity

A : Area yang dapat digunakan

V/a : (Visitor / area) Area yang diperlukan setiap pengunjung

Rf : rotation factor (Waktu yang diberikan pengelola/rata-rata durasi kunjungan)

Hasil perhitungan kemudian dianalisis dengan metode analisis deskriptif. Data yang dikumpulkan selanjutnya disusun, dijelaskan dan dianalisis.

\section{Hasil dan Diskusi}

Deskripsi Kawasan Pantai Kondang Merak: Kondang Merak merupakan salah satu destinasi wisata pantai yang berada di Malang Selatan-Jawa Timur. Menurut informasi yang didapatkan dari informan diketahui bahwa Pantai Kondang Merak menjadi destinasi wisata dari tahun 1990. Nama Kondang Merak berasal dari kata kondang yang berarti muara dan di muara tersebut banyak merak yang berkumpul sehingga dinamakan Pantai Kondang Merak. Tahun 1990 Kondang Merak sudah menjadi destinasi wisata di Malang Selatan yang pada awalnya dikelola sendiri oleh masyarakat. Namun dari akhir tahun 2017 hingga 2018 Kondang Merak dikelola oleh LMDH (Lembaga Masyarakat Desa Hutan) dengan pembagian hasil 48\% untuk LMDH dan 62\% untuk pemerintah. Pantai Kondang Merak beroperasi dari pukul 08.00 - 16.00 WIB dengan panjang tepi pantai $500 \mathrm{~m}$ dan lebar $50 \mathrm{~m}$, sehingga luas area yang digunakan yaitu $25.000 \mathrm{~m}^{2}$.

Menurut informasi yang didapatkan dari informan bahwa Pantai Kondang Merak menawarkan berbagai kegiatan seperti selam dan snorkeling. Kegiatan selam di Kondang Merak berjarak 5 mil $(8.047 \mathrm{~km})$ dari tepi pantai serta memiliki 3 spot dive yaitu gua, ikan dan terumbu karang dengan luas area yang digunakan pada setiap spot berukuran $50 \mathrm{~m} \times 10 \mathrm{~m}$ maka setiap spot dive memiliki luas 500 $\mathrm{m}^{2}$. Sehingga total luas area yang digunakan untuk kegitan selam yaitu $1500 \mathrm{~m}^{2}$. Kegiatan snorkeling yang dilakukan di Kondang Merak berjarak $0.5 \mathrm{mil}(0.804 \mathrm{~km})$ dari bibir pantai. Hal ini dikarenakan pada spot tersebut terdapat terumbu karang dan tempat berbagai macam ikan berkumpul. Area yang digunakan untuk kegiatan snorkeling seluas $2 \mathrm{Ha}\left(20.000 \mathrm{~m}^{2}\right)$. Hal ini dikarenakan atauran yang telah dibuat oleh pihak pengelola menghasilkan kesepakatan bahwa kawasan yang dapat digunakan untuk kegiatan snorkeling sebesar $2 \mathrm{Ha}$.

Sebagai salah satu tempat destinasi wisata Kondang Merak memerlukan berbagai kebutuan dan pelayanan. Kebutuhan dan pelayanan destinasi wisata harus didukung dengan tiga komponen yaitu aksesibilitas, atraksi dan amenitas. Aksesibilitas adalah tersedianya sarana yang membuat pengunjung memiliki kemudahan untuk menjangkau destinasi wisata, dalam hal ini tersedianya sarana transportasi menuju destinasi wisata dan jarak destinasi wisata yang terjangkau menjadi hal yang penting [12]. Atraksi yaitu daya tarik yang terdapat di destinasi wisata seperti keindahan dan keunikan alam, budaya dan aktifitas masyarakat setempat, peninggalan bangunan bersejarah, serta atraksi buatan seperti sarana permainan dan hiburan. Amenitas merupakan tersedianya sarana penunjang kebutuhan 
pengunjung selama melakukan kegiatan wisata, seperti tersedianya penjual makanan, minuman, akomodasi dan cinderamata [13].

Berdasarkan hasil wawancara yang telah dilakukan diketahui bahwa aksesibilitas menuju Kondang Merak memiliki kondisi jalan utama yang tergolong buruk. Hal ini dikarenakan terdapat pembangunan Jalur Lintas Selatan (JLS) yang menyebabkan disepanjang jalan utama masih terdapat bebatuan dan tekstur tanah yang belum rata, sehingga wisatawan akan mengalami sedikit kesulitan ketika melintasi jalan tersebut. Ketika musim hujan jalan menuju Kondang Merak tidak dapat dilalui dikarenakan jalan akan menjadi berlumpur dan licin (Gambar 2a). Namun, terdapat jalan yang telah diperbaiki oleh pengelola, jalan tersebut memiliki panjang $110 \mathrm{~m}$ dari pintu masuk Kondang Merak (Gambar 2b), sehingga keadaan jalan masih cukup nyaman untuk dilalui.
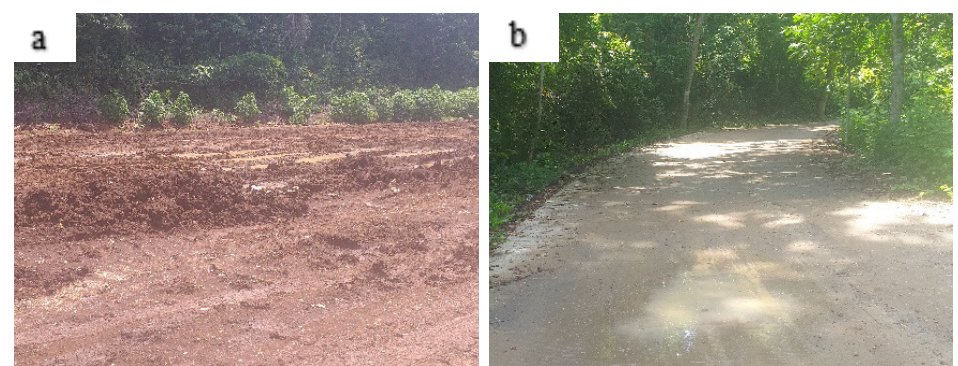

Gambar 2: Kondisi jalan menuju Kondang Merak: a) Buruk, b) Baik [14]

Jarak dari jalan utama menuju Kondang Merak sejauh $5 \mathrm{~km}$ dengan waktu tempuh 45 menit. Tidak terdapat sarana transportasi yang disediakan oleh pengelola untuk menuju Kondang Merak, sehingga wisatawan dapat menggunakan kendaraan pribadi untuk masuk ke Kondang Merak. Akses informasi mengenai Kondang Merak mudah didapatkan dan informasi yang diberikan cukup banyak. Sebagian besar wisatawan mendapatkan informasi melalui sosial media seperti Instagram, namun tidak sedikit wisatawan yang mendapatkan informasi dari wisatawan lain yang pernah berkunjung ke Kondang Merak. Menurut Rossadi dan Widayati [15] menyatakan bahwa aksesibilitas adalah suatu kemudahan dalam mencapai daerah tujuan wisata baik secara jarak geografis atau kecepatan teknis, serta tersedianya sarana transportasi menuju lokasi tujuan tersebut. Terdapat 3 persyaratan aksesibilitas yaitu akses informasi dimana fasilitas mudah ditemukan dan mudah dicapai, harus memiliki akses kondisi jalan yang dapat dilalui dan sampai ke tempat wisata serta harus ada akhir dari tempat suatu perjalanan (tempat parkir).

Atraksi yang disediakan oleh pengelola Kondang Merak untuk menarik wisatawan meliputi natural attraction, dan cultural attraction. Berdasarkan hasil pengamatan dan wawancara yang telah dilakukan natural attraction yang terdapat di Kondang Merak seperti snorkeling, menyelam, memancing, beranang dan menikmati keindahan pantai (Gambar 3). Sedangkan cultural attraction meliputi pertunjukan seni kuda lumping (Gambar 3) yang ditampilkan oleh warga Sumberbening dan kegiatan larung saji. Kegiatan seni kuda lumping dan larung saji ini diadakan setiap satu suro dan acara tersebut merupakan acara tahunan yang diadakan setiap satu tahun sekali. Larung saji ini dilakukan untuk menunjukkan rasa syukur kepada Yang Maha Esa serta harapan agar hasil petik laut melimpah pada tahun tersebut. Menurut Rossadi \& Widayati [15] menyatakan bahwa atraksi wisata yang baik dapat mendatangkan wisatawan sebanyak-banyaknya, menahan mereka di tempat atraksi dalam waktu yang cukup lama dan memberikan kepuasan kepada wisatawan yang berkunjung. Untuk mencapai hasil tersebut ada beberapa syarat yang harus dipenuhi yaitu, kegiatan (act) dan objek (artifact) yang merupakan atraksi itu sendiri harus dalam keadaan yang baik. Hal ini dikarenakan atraksi wisata harus disajikan di hadapan wisatawan maka cara penyajinya harus tepat. Atraksi wisata adalah terminal dari suatu mobilitas spasial suatu perjalanan. Oleh karena itu harus memenuhi semua determinan mobilitas spasial yaitu akomodasi, transportasi, dan promosi serta pemasaran serta keadaan ditempat atraksi harus dapat menahan wisatawan cukup lama [16]. 

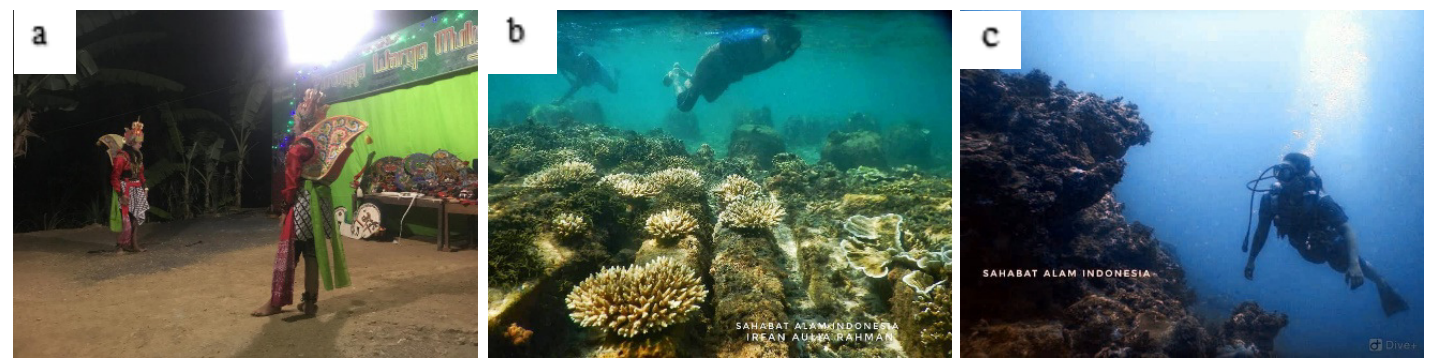

Gambar 3: Atraksi di Kondang Merak: a) Kuda Lumping [14] b) Snorkeling, c) Selam [17]

Tabel 1. Amenitas Kondang Merak

\begin{tabular}{clc}
\hline No & \multicolumn{1}{c}{ Amenitas } & Jumlah (buah) \\
\hline 1. & Rumah makan & 19 \\
2. & Toilet & 38 \\
3. & Mushola & 1 \\
4. & Gereja & 1 \\
5. & Penyewaan alat selam & 3 \\
6. & Penyewaan tikar & 3 \\
7. & Penyewaan tenda & 2 \\
8. & Loket & 1 \\
9. & Penginpan & 1 \\
10. & Toko souvenir & 1 \\
11. & Tempat sampah & 14 \\
12. & Klinik kesehatan & 1 \\
13. & Penyewaan perahu & 2 \\
\hline
\end{tabular}

Komponen lain yang perlu diperhatikan yaitu amenitas. Amenitas atau sarana dan prasarana yang disediakan oleh pengelola yang seperti tempat parkir. Tempat parkir yang disediakan oleh pengelola memiliki ukuran 25 x 50 m untuk kendaraan roda dua. Sedangkan untuk kendaraan roda empat belum terdapat parkir khusus, sehingga wisatawan bebas untuk memarkirkan kendaraannya di area Kondang Merak. Hal ini karena keterbatasan lahan yang tersedia. Namun petugas juga menentukan tempat mana yang dapat digunakan untuk parkir roda empat.

Amenitas lain yang dimiliki yaitu tempat ibadah seperti masjid dan gereja, 19 tempat makan, 38 toilet, 3 tempat penyewaan alat selam, 3 penyewaan tikar, 2 penyewaan tenda, loket, penginapan 1 toko souvenir, 14 buah tempat sampah, 1 klinik kesehatan dan penyewaan perahu (Tabel 1) (Gambar 4). Kondisi sarana dan prasarana yang tersedia masih bagus dan terawat seperti tempat ibadah yang tersedia selalu rutin dibersihkan oleh petugas kebersihan di Kondang Merak. Selain itu jumlah sarana yang tersedia sudah memadahi. Menurut Armono dkk [18] menyatakan bahwa dibutuhkan toilet sebanyak 5 buah, dan kamar mandi 2 buah untuk setiap 500 pengunjung, serta setidaknya terdapat 60 100 buah penginapan /ha. Sehingga dapat diketahui bahwa beberapa sarana yang tersedia di Kondang Merak sudah memadahi. Namun untuk jumlah penginapan belum sesuai dengan kebutuhan, akan tetapi meskipun jumlah penginapan yang tersedia belum mencukupi, pengelola telah menyediakan penyewaan tenda.

Menurut Rossadi dan Widayati [15] amenitas berkaitan dengan sarana akomodasi, restoran, toilet umum, rest area, souvenir shop, tempat parkir, tempat ibadah dan lain-lain yang harus ada di suatu destinasi wisata. Menurut Abdulhaji \& Yusuf [16] menyatakan bahwa fasilitas objek wisata berperan penting dalam mencapai hasil yang berkualitas. Semakin baik fasilitas yang diberikan kepada 


\section{e-Jurnal Ilmiah BIOSAINTROPIS (BIOSCIENCE-TROPIC)}

Volume 6/ No.: 2 / Halaman 1 - 10 / Januari Tahun 2021

ISSN : 2460-9455 (e) - 2338-2805(p)

pengunjung maka semakin baik pula citra objek wisata. Dengan tersedianya sarana maka akan mendorong calon wisatawan untuk berkunjung dan menikmati objek wisata dengan waktu yang relatif lama. Sarana dan pelayanannya akan memudahkan orang berkunjung ke objek wisata yang diinginkan serta pergerakan di lokasi wisata. Menurut PERMENPAR No 3 Tahun 2018 peningkatan fasilitas wisata meliputi pembangunan pusat informasi, runag ganti/toilet, pergola, gazebo, lampu tanam, pagar pembatas, panggung kesenian, kios cinderamata, pusat jajanan kuliner, tempat ibadah, menara pandang, gapura identitas, pembuatan jalur pejalan kaki (pedestrian)/jalan setapak/jalan dalam kawasan, boardwalk, tempat parkir; dan pembuatan rambu-rambu petunjuk arah.
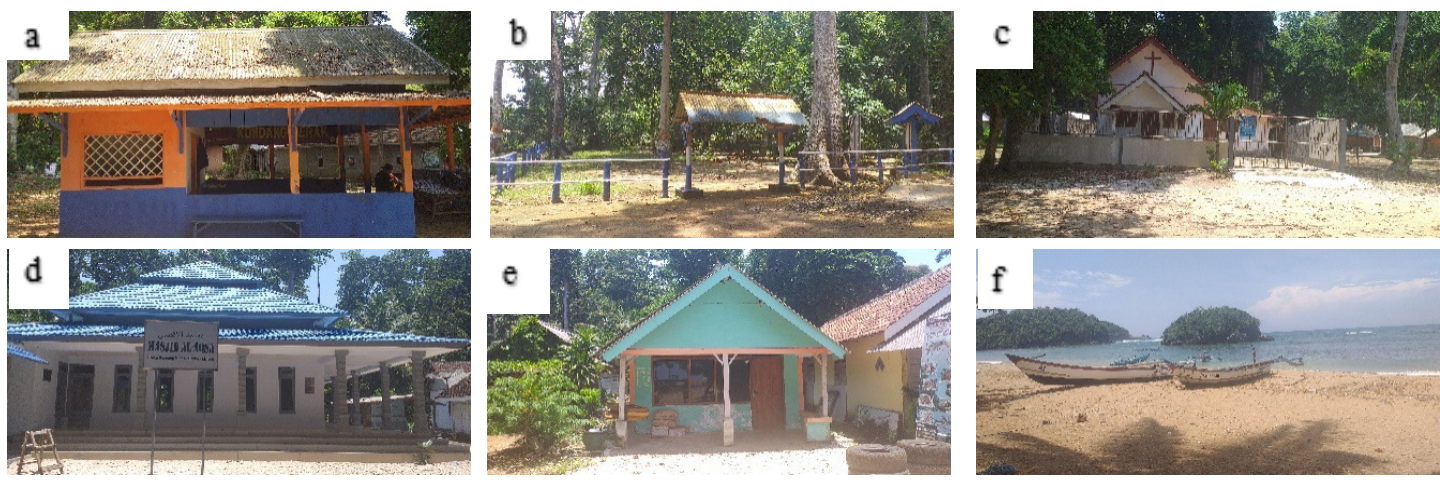

Gambar 4: Amenitas di Kondang Merak: a) loket, b) tempat parkir, c) Gereja, d) Masjid,

e) penginapan, f) penyewaan perahu [14]

Daya Dukung Fisik Kegiatan Akuatik di Kondang Merak: Daya dukung kawasan sangat menentukan keberlanjutan suatu kegiatan wisata. Daya dukung setiap kawasan wisata berbeda satu wilayah dengan wilayah lainnya hal ini dikarenakan berkaitan dengan jenis wisata yang akan dikembangkan [19]. Kagiatan akuatik yang dapat dilakukan di Kondang Merak meliputi snorkeling, menyelam, berenang, memancing dan melihat lumba-lumba. Namun pada penelitian ini perhitungan daya dukung dilakukan untuk kegiatan snorkeling dan menyelam. Hal ini dikarenakan kedua kegiatan tersebut masih dikembangkan oleh pengelola Kondang Merak.

Tabel 2. Perhitungan daya dukung fisik selam

\begin{tabular}{ccr}
\hline Simbol & Parameter & Nilai \\
\hline A & Area yang dapat digunakan $\left(\mathrm{m}^{2}\right)$ & 1.500 \\
V/a & Area yg diperlukan setiap pengujung $\left(\mathrm{m}^{2}\right)$ & 0,001 \\
Rf & Rotation factor (/hari) & 2 \\
PCC & Physical Carrying Capacity (orang) & 3 \\
\hline
\end{tabular}

Menurut informasi yang diberikan oleh informan diketahui bahwa kegiatan wisata selam di Kondang Merak terbagi menjadi tiga dive spot yang memiliki pemandangan berbeda seperti gua, ikan, dan terumbu karang, dengan luas setiap dive spot $50 \mathrm{~m} \times 10 \mathrm{~m}$ sehingga total wilayah yang digunakan untuk menyelam yaitu $1.500 \mathrm{~m}^{2}$.Jarak antara dive spot dan bibir sejauh 5 mil atau kurang lebih 8,047 
e-Jurnal Ilmiah BIOSAINTROPIS (BIOSCIENCE-TROPIC)

Volume 6/ No.: 2 / Halaman 1 - 10 / Januari Tahun 2021

ISSN : 2460-9455 (e) - 2338-2805(p)

$\mathrm{km}$. Waktu yang diberikan oleh pengelola untuk melakukan kegiatan selam yaitu 2 jam. Sedangkan waktu perjalan yang digunakan untuk perjalan pulang dan pergi yaitu selama 2 jam. Sehingga total waktu yang diperlukan dalam kegiatan menyelam selama 4 jam. Waktu yang disediakan oleh pengelola yaitu dari pukul 08.00 - 16.00 WIB. Oleh karena itu, rotation factor yang didapatkan 2 . Berdasarkan perhitungan daya dukung fisik menggunakan rumus 2 serta dari data yang telah didapatkan diketahui bahwa daya dukung fisik kegiatan selam yaitu sebesar 3 orang/hari (Tabel 2).

Tabel 3. Perhitungan daya dukung fisik snorkeling

\begin{tabular}{ccr} 
Simbol & Parameter & \multicolumn{1}{c}{ Nilai } \\
\hline A & Area yang dapat digunakan $\left(\mathrm{m}^{2}\right.$ & 20.000 \\
V/a & Area yg diperlukan setiap pengujung $\left(\mathrm{m}^{2}\right)$ & 0,002 \\
Rf & Rotation factor (/hari) & 1 \\
PCC & Physical Carrying Capacity (orang) & 40 \\
\hline
\end{tabular}

Kegiatan akuatik yang dapat dilakukan oleh wisatawan selain menyelam yaitu snorkeling. Menurut informasi yang didapatkan dari informan diketahui bahwa luas kawasan yang digunakan untuk kegiatan ini sebesar $2 \mathrm{Ha}$ atau $20.000 \mathrm{~m}^{2}$. Hal ini dikarenakan aturan yang dibuat oleh pihak pengelola menghasilkan kesepakatan bahwa kawasan yang dapat digunakan untuk aktivitas snorkeling sebesar $2 \mathrm{Ha}$. Selain itu pada kawasan tersebut terdapat terumbu karang dan berbagai jenis ikan yang berkumpul.

Menurut informasi yang telah didapatkan kegiatan wisata snorkeling di Kondang Merak berjarak 0.5 mil dari bibir pantai atau $0,804 \mathrm{~km}$. Kegiatan snorkeling hanya dapat dilakukan ketika laut surut yaitu pada pukul 10.00 - 13.00 WIB. Sehingga kegiatan snorkeling hanya dapat dilakukan 1 kali dalam sehari serta memiliki rotation factor 1. Berdasarkan perhitungan daya dukung fisik menggunakan rumus 2 diketahui jumlah maximum wisatawan yang secara fisik dapat ditampung untuk melakukan snorkeling yaitu sebanyak 40 orang (Tabel 3).

Perhitungan daya dukung kegiatan selam dan snorkeling memiliki jumlah maximum wisatawan yang dapat ditampung berbeda-beda, baik secara fisik maupun ekologi. Hal ini dikarenakan luas area yang digunakan pada kegiatan snorkeling dan selam berbeda. Kegiatan snorkeling menggunakan luas lahan sebesar $20.000 \mathrm{~m}^{2}$ atau $2 \mathrm{ha}$, sedangkan untuk kegiatan selam luas area yang digunakan sebesar $1.500 \mathrm{~m}^{2}$. Selain itu rotation factor untuk melakukan snorkeling dan selam berbeda, dimana kegiatan selam memiliki nilai rotation factor 2 sedangkan untuk kegiatan snorkeling memiliki nilai rotation factor 1 . Hal ini dikarenakan kegiatan snorkeling hanya dapat dilakukan ketika laut mulai surut.

Daya Dukung Fisik Kegiatan Terestrial di Kondang Merak: Berbagai jenis aktivitas yang dapat dilakukan di daerah terrestrial Pantai Kondang Merak seperti berjemur, melihat pemandangan pantai, berjalan kaki sepanjang pantai, dan menikmati kuliner khas Kondang Merak. Menurut informasi yang didapatkan dari informan kawasan pantai dengan panjang pantai pasir putih yang dapat digunakan yaitu sepanjang $500 \mathrm{~m}$ dengan lebar $50 \mathrm{~m}$. Sehingga luas area yang dapat digunakan untuk kegiatan rekreasi pantai yaitu sebesar $25.000 \mathrm{~m}^{2}$. Menurut infomasi yang didapatkan dari hasil wawancara pantai Kondang Merak mulai beroperasi pada pukul $08.00-16.00$ WIB dan sebagian besar wisatawan menghabiskan waktu selama 4 jam untuk melakukan berbagai kegiatan di Pantai Kondang Merak. Sehingga rotation factor pada kegiatan rekreasi pantai yaitu 2. Hasil rotation factor didapatkan dari perhitungan waktu yang disediakan oleh pengelola dibagi oleh waktu yang dihabiskan oleh pangunjung. Sehingga diketahui hasil perhitungan daya dukung 
e-Jurnal Ilmiah BIOSAINTROPIS (BIOSCIENCE-TROPIC)

Volume 6/ No.: 2 / Halaman 1 - 10 / Januari Tahun 2021

ISSN : 2460-9455 (e) - 2338-2805(p)

Tabel 4. Perhitungan daya dukung fisik rekreasi pantai

\begin{tabular}{ccr} 
Simbol & Parameter & \multicolumn{1}{c}{ Nilai } \\
\hline A & Area yang dapat digunakan $\left(\mathrm{m}^{2)}\right.$ & 25.000 \\
V/a & Area yg diperlukan setiap pengujung $\left(\mathrm{m}^{2}\right)$ & 0,02 \\
Rf & Rotation factor (/hari) & 2 \\
PCC & Physical Carrying Capacity (orang) & 1.000 \\
\hline
\end{tabular}

fisik menggunakan rumus 2 jumlah maximum wisatawan yang secara fisik dapat ditampung untuk melakukan rekreasi pantai yaitu sebanyak 1000 orang/hari (Tabel 4). Menurut informasi yang telah didapatkan diketahui bahwa jumlah pengunjung yang datang ke Pantai Kondang Berkisar 50-100 orang/hari. Namun, jumlah pengunjung dapat melebihi 1.000 orang/hari ketika hari libur. Jumlah pengunjung yang melebihi daya dukung dapat mengakibatkan kenyamanan pengunjung berkurang dan dapat mempengaruhi kelestarian ekosistem didalamnya, sehingga diperlukan pembatasan jumlah pengunjung. Menurut Trakolis [20] menyatakan bahwa kegiatan rekreasi memiliki dampak terhadap ekologi seperti penurunan ketinggian vegetasi dan penurunan jumlah spesies yang ada.

\section{Kesimpulan}

Daya dukung fisik kegiatan selam di Kondang Merak yaitu sebesar 3 orang/hari sedangkan dan daya dukung fisik untuk kegiatan snorkeling di Kondang Merak yaitu sebanyak 40 orang/hari. Selain itu, daya dukung kegiatan wisata terestrial di Kondang Merak memiliki nilai daya dukung fisik sebanyak 1000 orang/hari. Namun, jumlah pengunjung dapat melebihi kapasitas daya dukung fisik sehingga diperlukan pembatasan jumlah pengunjung agar kelestarian ekosistem didalamnya dapat terjaga.

\section{Daftar Pustaka}

[1] Hakim, L. and Nakagoshi, N. 2008. Planning for nature-based tourism in East Java: recent status of biodiversity, conservation, and its implication for sustainable tourism. ASEAN Journal on Hospitality and Tourism. 7:155-167.

[2] Yulisa, E. N., Johan, Y. dan Hartono, D. 2016. Analisis kesesuaian dan daya dukung ekowisata pantai kategori rekreasi Pantai Laguna Desa Merpas Kabupaten Kaur. Jurnal Enggano. 1(1):97-111.

[3] Yulius, Rahmania. R., Kadarwati. U. R., Ramdhan, M., Khairunnisa, T., Saepuloh, D., Subandriyo, J., dan Tussadiah, A. 2018. Buku Panduan Kriteria Penetapan Zona Ekowisata Bahari. IPB Press. Bogor.

[4] Satria, D. 2009. Strategi pengembangan ekowisata berbasis ekonomi lokal dalam rangka program pengentasan kemiskinan di wilayah Kabupaten Malang. Journal of Indonesian Applied Economics. 3(1):37-47.

[5] Fama, A., Haeruddin, Purwanti, F. 2017. Kesesuaian dan daya dukung pemanfaatan pantai kartini jepara sebagai destinasi wisata pantai. Jurnal Ilmu dan Teknologi Kelautan Tropis. 9(2):805813. 
e-Jurnal Ilmiah BIOSAINTROPIS (BIOSCIENCE-TROPIC)

Volume 6/ No.: 2 / Halaman 1 - 10 / Januari Tahun 2021

ISSN : 2460-9455 (e) - 2338-2805(p)

[6] Luthfi, O. M., Alviana, P. Z., Guntur, Sunardi. Jauhari, A. 2016. Distribution of massive porites at reef flat in Kondang Merak, Malang, Indonesia. Research Journal of Life Science. 3(1):2330.

[7] Aris, S. dan Aunurohim. 2013. Studi keanekaragaman avifauna sebagai sarana edukasi ekowisata birdwatching di kawasan wisata Kondang Merak, Malang. Jurnal Sains Dan Seni Pomits. 2(1):2337-3520.

[8] Luthfi, O. M, and Setianingsih, M. 2018. Application of ethnography method in conservation area efforts by SALAM, the conservation and social community empowerment organization, at Kondang Merak Beach, District of Malang. ECSOFiM: Economic and Social of Fisheries and Marine Journal. 6(1):1-13.

[9] Pangemanan, A. P. 2012. Model optimalisasi ekonomi kawasan ekowisata Taman Nasional Bunaken Sulawesi Utara. Program Pascasarjana Fakultas Pertanian. Universitas Brawijaya. Malang. Disertasi.

[10] Ceballos-Lascurain, H. 1996. Tourism, Ecotourism and Protected Areas: The State of NatureBased Tourism Around The World and Guidelines for Its Development. IUCN, Gland, Switzerland and Cambridge, UK.

[11] Cifuentes Arias, M. 1992. Determinacion de Capacidad de Carga Turistica en Areas Protegidas. CATIE, Turrialba, Costa Rica.

[12] Setyanto, I., dan Pangestuti, E. 2019. Pengaruh komponen destinasi wisata (4A) terhadap kepuasan pengunjung Pantai Gemah Tulungagung. Jurnal Administrasi Bisnis. 72(1):157167.

[13] Wanda, I.B.K., dan Pangestuti, E. 2018. Pengaruh pengembangan komponen destinasi wisata terhadap kepuasan pengunjung (Survei pada Pengunjung Situs Trowulan). Jurnal Administrasi Bisnis. 55(3):83-91.

[14] Anggraeni, S. 2020. Dokumentasi pribadi. 24 Februari 2020.

[15] Rossadi, L. N. dan Widayati, E. 2018. Pengaruh aksesibilitas, amenitas, dan atraksi wisata terhadap minat kunjungan wisatawan ke Wahana Air Balong Waterpark Bantul Daerah Istimewa Yogyakarta. Journal of Tourism and Economic. 1(2):109-116.

[16] Abdulhaji, S., dan Yusuf, I, S, H. 2016. Pengaruh atraksi, aksesibilitas, dan fasilitas terhadap citra objek wisata Danau Tolire Besar di Kota Ternate. Jurnal Penelitian Humano. 7(2):134148.

[17] SALAM. 2019. Kamunikasi pribadi. 27 Februari 2020.

[18] Armono, H. D., Rosyid, D. M., and Nuzula, N. I. 2017. Carrying capacity model applied to coastal ecotourism of Baluran National park, Indonesia. IOP Conf. Series: Earth and Environmental Science. 1-8.

[19] Yulianda, F., Samosir, A., Fachrudin, A., Adimu, H. E., Febryane, A., dan Muhidin. 2017. Daya Dukung Lingkungan di Taman Nasional Kepulauan Seribu. Direktorat Pemanfaatan Jasa Lingkungan Hutan Konservasi.

[20] Trakolis, D. 2003. Carrying capacity - an old concept: significance for the management of urban forest resources. New Medit. 3:58-64. 